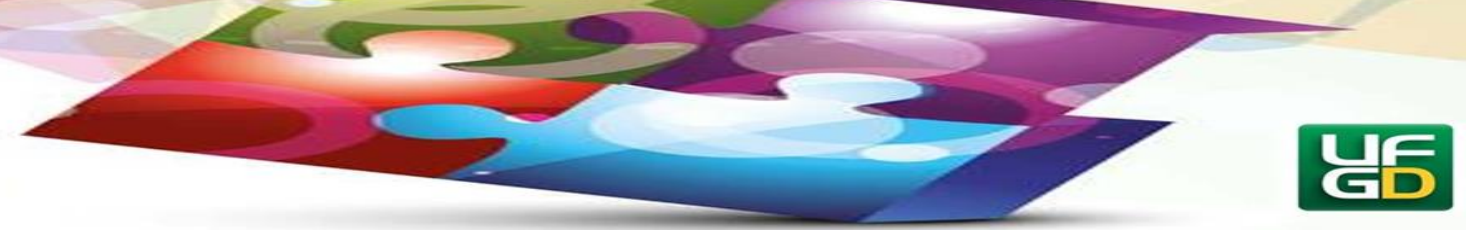

\title{
CANTIGAS DE RODA E BRINCADEIRAS CANTADAS: O LÚDICO E SUA CONTRIBUIÇÃO PARA EDUCAÇÃO INFANTIL
}

\section{WHEELCHAIRS AND SINGLE JOBS: LÚDICO AND ITS CONTRIBUTION TO CHILDREN'S EDUCATION}

\author{
Martha GONÇALVES ${ }^{1}$
}

Marina VINHA ${ }^{2}$

\begin{abstract}
Resumo: esta pesquisa trata das contribuições de dois tipos de práticas corporais, 'cantigas de roda' e 'brincadeiras cantadas'. O objetivo geral do estudo foi relatar as contribuições destas práticas na Educação Infantil. Os objetivos específicos foram: caracterizar a infância, o nível de ensino voltado para a infância e as indicações de conteúdos caracterizados como práticas corporais. $\mathrm{O}$ estudo foi problematizado com a seguinte pergunta: Quais contribuições tais práticas corporais proporcionam à formação da criança no nível de escolaridade da Educação Infantil, nos aspectos social, motriz e afetivo? O referencial teórico foi obtido em: Bréscia (2003), Queiroz (2006) e Gallahue e Donnely (2008). O estudo foi de caráter bibliográfico. A metodologia seguiu os seguintes passos: a) escolha do tema motivado pela atuação da acadêmica com o nível de ensino da Educação Infantil; b) seleção dos autores de referência; c) elaboração do projeto e pesquisa bibliográfica; d) escrita do texto.
\end{abstract}

Palavras-chave: Ludicidade. Práticas Corporais. Aprendizado. Âmbito Escolar.

Abstract: this research deals with the contributions of two types of embodied practice, 'wheel songs' and 'jokes' sung. The general objective of the study was to report the contributions of these practices in Early Childhood Education. The specific objectives were: to characterize childhood, the level of education directed towards childhood and the indications of contents characterized as corporal practices; The study was questioned with the following question: What contributions do such corporal practices provide to the formation of the child in the level of education of the Child, in the social, motive and affective aspects? The theoretical reference was obtained in: Brescia (2003), Queiroz (2006) and Gallahue and Donnely (2008). The study was of bibliographic character. The methodology followed the following steps: a) choice of topic is motivated by performance of academically with the level of education of Early Childhood Educstion; b) selection authors of reference; c) elaboration of the project and bibliographic research; d) writing the text.

Keywords: Loudeness. Bodily Practices. Learning. School Scope.

\footnotetext{
${ }^{1}$ Discente do $8^{\circ}$ Semestre de Pedagogia da Faculdade de Educação (FAED) da Universidade Federal da Grande Dourados (UFGD). E-mail: martha.gonçalves@ hotmail.com

${ }^{2}$ Professora Associada da FAED/UFGD. E-mail: marinavinha@ufgd.edu.br
} 


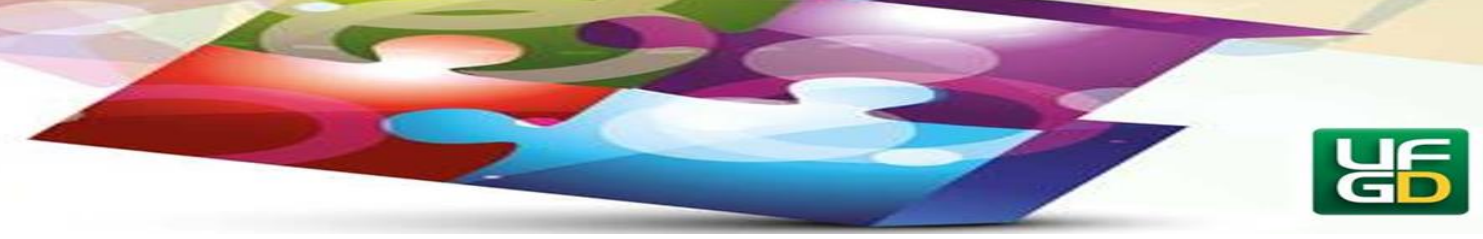

Introdução

Este artigo é resultado do Trabalho de Graduação (TG), o qual apresenta uma reflexão sobre as temáticas 'cantigas de roda' e 'brincadeiras cantadas', ambas práticas corporais de caráter lúdico, usuais como conteúdos pedagógicos na Educação Infantil. As práticas realizadas com a formação em 'roda' são ritmadas por cantos realizados geralmente, pelos próprios praticantes. Assim, também, são as 'brincadeiras cantadas', cujas letras remetem aos sons onomatopeicos e de instrumentos, falando de amor, casamento, animais, sendo que muitas vezes são desafiadores para os praticantes. As duas formas de práticas corporais contribuem para educação das crianças no âmbito escolar (PALHETA, 2007).

Nesse contexto, o objetivo geral do estudo é o de relatar as contribuições dos conteúdos, práticas corporais 'cantigas de roda' e 'brincadeiras cantadas' na Educação Infantil. Os objetivos específicos são: caracterizar a infância, o nível de ensino voltado para a infância e as indicações de conteúdos caracterizadas como práticas corporais; e identificar as cantigas de roda e as brincadeiras cantadas segundo critérios científicos. O estudo foi problematizado com a seguinte pergunta: Quais contribuições as práticas corporais 'cantigas de roda' e 'brincadeiras cantadas' proporcionam à formação da criança no nível de escolaridade da Educação Infantil, nos aspectos intelectual, motriz e afetivo? A relevância do presente estudo, para os professores de Educação Infantil é no sentido de compreender cientificamente quais são os benefícios trazidos por ambas as práticas corporais, no desenvolvimento intelectual, motriz e afetivo das crianças. Frente ao fato de que tais práticas são usualmente conhecidas como 'brincadeiras', podem ter sua importância minimizada na academia e na formação dos professores.

A pesquisa é do tipo bibliográfico, que segundo Lakatos e Marconi (2003) caracterizase por procurar explicações a partir de referências teóricas já publicadas, pois coloca o pesquisador em contato com o que já foi escrito sobre o assunto. A pesquisa bibliográfica exige uma atitude crítica diante dos documentos, artigos científicos, livros e outros materiais de pesquisa. No projeto bibliográfico o pesquisador deve posicionar-se numa postura de comprometimento e ética com a preservação da reflexão dos autores, na devida citação das fontes, no cuidado de não realizar nenhuma alteração, e plágio das obras pesquisadas. Gil (2002, p. 19) afirma que "o planejamento da pesquisa concretiza-se (sic) mediante a elaboração de um 


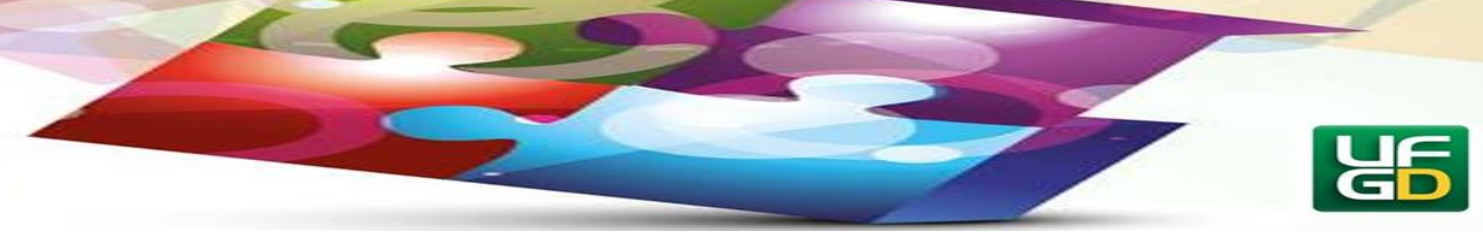

projeto, que é o documento explicitador das ações a serem desenvolvidas ao longo do processo de pesquisa".

A metodologia seguiu os seguintes passos: a) escolha do tema motivado pela atuação da acadêmica, voltado ao nível de ensino da Educação Infantil; b) seleção dos autores de referência; c) elaboração do projeto e pesquisa bibliográfica realizada de leituras; d) escrita do texto.

O referencial teórico foi obtido em: Bréscia (2003), Queiroz (2006), e Gallahue e Donnely (2008). O estudo foi complementado com a busca nos seguintes documentos: Base Curricular Comum Nacional (BCCN) (BRASIL, 2017), ainda não publicado oficialmente; e o Estatuto da Criança e do Adolescente (ECA) (BRASIL, 2016).

Nas considerações finais o estudo aponta a cientificidade e a assertividade das práticas corporais na formação da criança, na Educação Infantil.

\section{Práticas corporais - conceitos e justificativas}

Práticas corporais - conceitos e justificativas As 'práticas corporais' são assim denominadas por envolverem a criança no seu todo, ou seja, no aspecto intelectual/pensando, no motriz/agindo, no afetivo/envolvendo-se social e afetivamente, sempre em ações lúdicas, sejam na forma de jogos, danças, lutas, brincadeiras, dentre outras (SILVA; DAMINANE, 2006).

Na Educação Física, o termo ‘práticas corporais' vem sendo adotado por pesquisadores voltados aos estudos do campo das Ciências Humanas e Sociais. Autores mais voltados ao campo das Ciências Biológicas e Exatas adotam o termo 'atividades físicas'. Como o presente estudo está voltado para a área da Educação, e a Educação Física escolar compõe a grande área Linguagens, o termo práticas corporais é o que melhor expressa o contexto educativo. As práticas corporais são "identificadas como manifestações culturais que enfocam a dimensão corporal” (FALCÃO; SARAIVA, 2009, p. 19).

Os supracitados autores recorreram a Mauss (2003, apud. FALCÃO; SARAIVA, 2009, p. 23), para afirmar que:

O conjunto de práticas, hábitos, costumes, crenças e tradições que caracteriza uma cultura não apenas se refere ao corpo, como é no corpo que encontra sua principal objetivação, a partir das diferentes técnicas corporais, e sua 


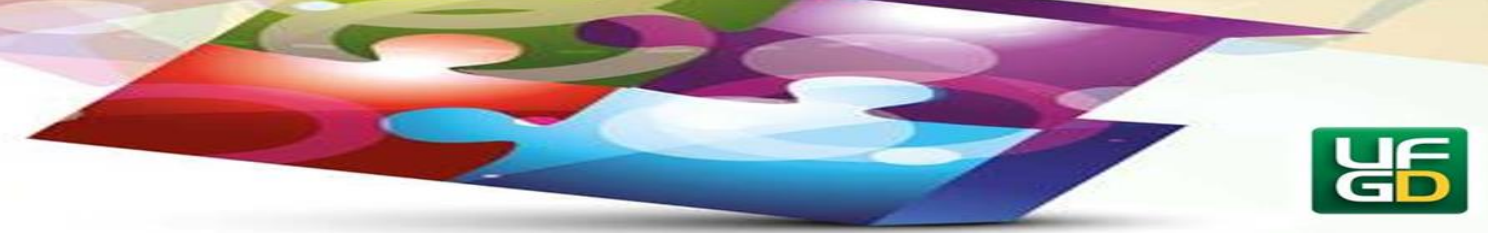

constituição em diferentes práticas culturais. Ao afirmar a cultura presente nas práticas corporais, os autores entendem que o gesto precede a linguagem e introduz o humano no mundo e o mundo no humano, constituindo uma experiência fundamental.

O mundo no humano, ou particularmente 'cada mundo cultural' pode ser traduzido em práticas corporais significativas, cujo caráter lúdico é responsável pela transmissão de cultura de um determinado povo e região com o intuito de socializar, ensinar e garantir a união, independente da idade que esteja (TEIXEIRA, 2010). Por isso, pesquisar sobre as diferentes infâncias, no caso voltado para as cantigas de roda e as brincadeiras cantadas, nos permite aproximar e compreender a cultura e história das crianças.

Entre os momentos que são expostos aos jogos, brincadeiras, cantos e danças, que estão ali presentes. Destacam-se a música e toda sua sonoridade envolvente e instrutiva, e os movimentos das cirandas e das danças acometidos pelas cantigas. Aliás, tendo o planejamento e a intervenção do professor na educação infantil, tendo como foco o progresso positivo da escrita e da fala da criança/aluno (LIRA, 2016, p. 1).

A sabedoria ensina que o ritmo tem poder para provocar mudanças no organismo físico, enquanto a melodia provoca alterações nos estados mental e emocional e a harmonia pode melhorar a compreensão da espiritualidade, argumenta Andrews (1996 apud ARTAXO, 2013, p.25). Segundo Kuzuyabu (2012), a música tem um poder muito grande sobre o indivíduo, por sua ação terapêutica, assim como por proporcionar uma grande sensação de prazer e alegria.

A contribuição da música na Educação Infantil, no caso as cantigas, são de extrema importância no desenvolvimento das crianças, principalmente no sentido das habilidades motrizes. As habilidades de força, equilíbrio, resistência, coordenação e flexibilidade são também desenvolvidas (KUZUYABU, 2012).

Souza (2015), ao ministrar aulas de dança para crianças afirma que as mesmas conhecem seu próprio mundo, se descobrem e, de uma forma lúdica, se socializam com outras crianças, ponto forte para trabalhar a autoestima e de forma criativa; além de contribuir para se libertar da timidez. Ao dançar e cantar a criança se descobre, começa a ter noção de ritmo, de lateralidade [direito-esquerda, frente-atrás], espaço, tempo, diversos andamentos e intensidades em diferentes pulsações. Ela também percebe que a música lhe traz um momento de alegria e descontração. Ao ser levada para casa, tanto as cantigas quanto suas movimentações, a criança 


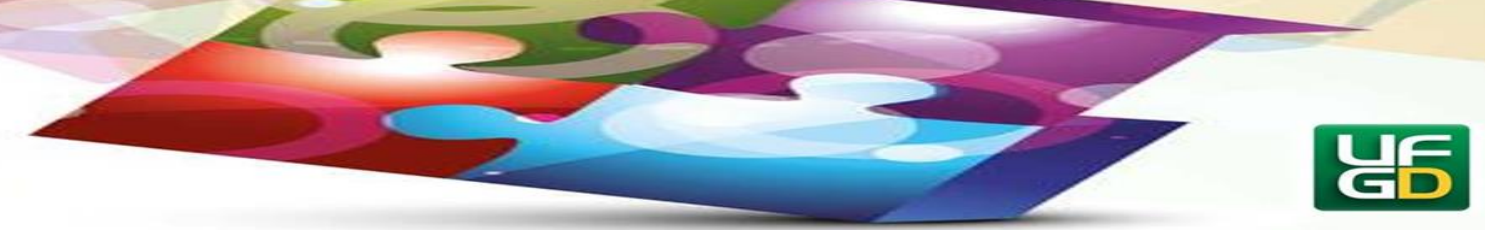

apresenta aos pais e familiares o conhecimento aprendido na escola e seu desenvolvimento em autoestima e desinibição.

Assim, as práticas corporais são temas fundamentados cientificamente, tanto pelo significado quanto pela contribuição na formação da criança. Cantar, dançar, correr, girar, saltitar, deslocar em duplas ou em grupo ao som de músicas, sejam elas cantadas ou instrumentalizadas, educam e divertem. O caráter lúdico é um bálsamo para as crianças envolvendo a totalidade corporal e abrangendo o sentido social, cognitivo e motriz (SILVA; DAMIANE, 2006).

\section{Caracterizações - Criança, Infância, Brincar e Educação Infantil}

O termo infância, segundo o Dicionário do Aurélio.com (2016) refere-se ao período da vida humana desde o nascimento até a puberdade. Infância e Criança são dois termos que promovem alguma confusão. Criança é menino ou menina no período da infância, desde filhote até uma década de vida, aproximadamente marcada por ser um sujeito histórico, de direito e que produz cultura (COHN, 2005).

Quando a criança chega à idade cronológica de 04 anos, a legislação brasileira indica que ela deva ser inserida no sistema escolarizável, no nível denominado Educação Infantil. Neste nível há professores especializados para atuarem com a criança. De acordo com o Estatuto da Criança e do Adolescente (ECA) a especialização com a Educação Infantil tem a oferecer a estes alunos elementos, conteúdos, práticas corporais e contextos pedagógicos que contribuam para o desenvolvimento das crianças. Nesse sentido, as práticas corporais brincadeiras cantadas e as cantigas de roda, muitas das quais fazem parte do acervo cultural trazido pelas crianças, são adotadas para o desenvolvimento intelectual, afetivo e motriz a ser realizado na escola (BRASIL, 2016; GALLAHUE \& DONELLY, 2008).

Em decorrência da importância do brincar para a criança, este elemento é levado para o interior da escola. Embora alguns pais entendam a ludicidade com preconceito, e a brincadeira dentro da sala de aula como 'uma perda de tempo', os educadores se esforçam esclarecendo os pais e a comunidade, e insistindo na premissa científica de que o brincar não só enriquece esta fase da escolaridade, mas é por meio dele que o processo de aprendizagem se constitui. Atualmente, os pesquisadores buscam formas e métodos para compreender as mudanças na 


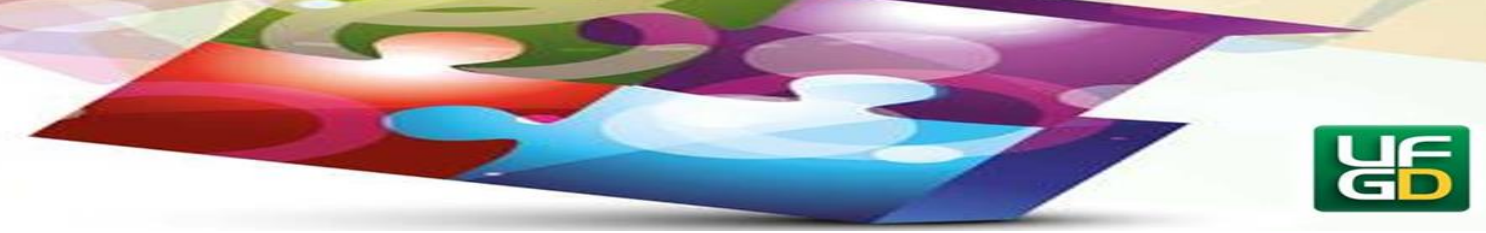

sociedade e, nesse sentido, os professores estão sendo conscientizados que criança e ludicidade caminham juntas. "No contexto educacional, as práticas pedagógicas lúdicas são voltadas para a alfabetização, de forma a contribuírem para o desenvolvimento global da criança." (ELKIND, 2004, p. 240).

A Educação Infantil caracteriza-se por uma etapa de escolaridade singular, por ser considerada a fase pré-escolar. Há diferentes indicações sobre esta fase de escolaridade, pois conforme a Rede de Ensino seja ela privada ou pública, as decisões sobre o encaminhamento dessa questão são definidas nos Planos Educacionais Municipais e Estaduais, e posteriormente, nos Projetos Políticos Pedagógicos (PPP) de cada unidade escolar. O presente estudo não enfatiza esta questão, apenas relata cientificamente as contribuições dos conteúdos, práticas corporais ‘cantigas de roda' e ‘brincadeiras cantadas' na Educação Infantil (QUEIROZ, 2006).

O fato é que, por ser a primeira vez que a criança participa de um ambiente não familiar, embora os pais estejam sempre acompanhando, pois a proximidade dos familiares é significativa no ambiente escolar. Mãe, pai, avós maternos e paternos, tios, primos, parentela em geral ou mesmo os responsáveis, devido às diferentes situações em que se encontram as crianças atualmente, interligam as raízes socioculturais da criança, de forma a contribuírem para o processo de desenvolvimento do conhecimento a ser sistematizado (GALLAHUE; DONNELY, 2008, COHN, 2005).

Para entender a infância, suas mudanças sociais e culturais, os educadores procuram compreender a criança e nesse sentido, as práticas lúdicas são prioritárias. Diante deste fato, Elkind (2004, p. 240) destaca que:

Não importa que filosofia de vida abracemos é importante encarar a infância como um estágio da vida, não simplesmente como a ante-sala da vida. Pressionar as crianças para serem adultas viola a santidade da vida, priorizando um período em detrimento de outro. Mas se realmente valorizarmos a vida humana, vamos valorizar cada período igualmente e dar a cada estágio da vida o que é adequado a este estágio.

Elkind (2004) e Cohn (2005) concordam que a fase de vida denominada infância é marcada pela cultura e é significativa na formação humana. Martins (2010) também corrobora com esta ideia e afirma ser necessário o brincar no cotidiano das crianças. Através do brincar a criança repete atitudes para se expressar e interagir na sociedade e quando brinca aprende coisas e situações que ninguém lhe ensinaria, pois é brincando que a socialização ocorre. 


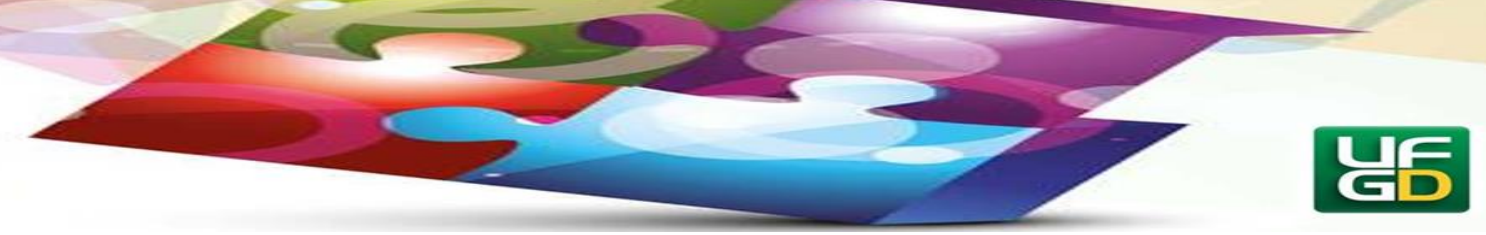

Cunha (2001, p. 28) afirma que "o brinquedo proporciona o aprender, fazendo e brincando". Quando se está brincando, a criança faz descobertas, e entra em um mundo imaginário de sonhos e fantasias. Diante disto, "tanto jogo quanto brincadeira contém a ideia de laço, relação, vínculo, pondo indivíduos em relação consigo mesmos, com os outros, com o mundo, enfim" (FORTUNA, 2004, p. 2). Quando a criança fica privada do brincar lhe faltará um excelente meio de aprendizagem. Portanto, o brincar deve estar presente, conectado com a aprendizagem e deve ser exercido em ambiente atraente e desafiador (MARTINS, 2010).

Para Luckesi (2005), o âmbito escolar é um espaço onde a criança pode vivenciar suas experiências lúdicas. Geralmente, a família tem oferecido poucos momentos de lazer para e com seus filhos, tanto por não terem tempo ou por falta de espaço. O fato é que quando as crianças brincam em grupo estão aprendendo a trabalhar coletivamente, a cooperar, dispendem energia e aumentam a força de vontade para alcançar objetivos. A criança trabalhando em grupo torna-se menos egocêntrica e mais participativa. Fortuna (2008, p. 465) destaca que: "Na brincadeira somos exatamente quem somos e, ao mesmo tempo, todas as possibilidades de ser estão nela contidas. Ao brincar exercemos o direito à diferença e a sermos aceitos mesmo diferentes ou aceitos por isso mesmo".

A legislação que proporciona sustentação para a Educação Infantil é a Lei de Diretrizes e Bases da Educação Nacional, n 9.394/1996, que estabelece de forma incisiva o vínculo entre o atendimento às crianças de zero a seis anos e a educação (BRASIL, 1996). O documento que fez referência, com indicações acerca dessa etapa de escolaridade, é o Referencial Curricular Nacional para Educação Infantil. Este documento traz um conjunto de orientações pedagógicas que visam contribuir com a implantação de práticas educativas de qualidade, de forma a "promover e ampliar as condições necessárias para o exercício da cidadania das crianças brasileiras" (BRASIL, 1996, p.13). A qualidade das experiências oferecidas e que contribuem para o exercício da cidadania da criança deve estar embasada nos seguintes princípios:

$\mathrm{O}$ respeito à dignidade e aos direitos da criança, consideradas nas suas diferenças individuais, sociais, econômicas, culturais, étnicas, religiosas, etc. $\mathrm{O}$ direito da criança a brincar, como forma particular de expressão, pensamento, interação e comunicação infantil. $\mathrm{O}$ acesso das crianças aos bens socioculturais disponíveis, relativas à expressão, à comunicação, à interação social, ao pensamento, à ética e à estética. A socialização das crianças por meio de sua participação e inserção nas mais diversificadas práticas sociais, sem discriminação de espécie alguma. $\mathrm{O}$ entendimento aos cuidados 


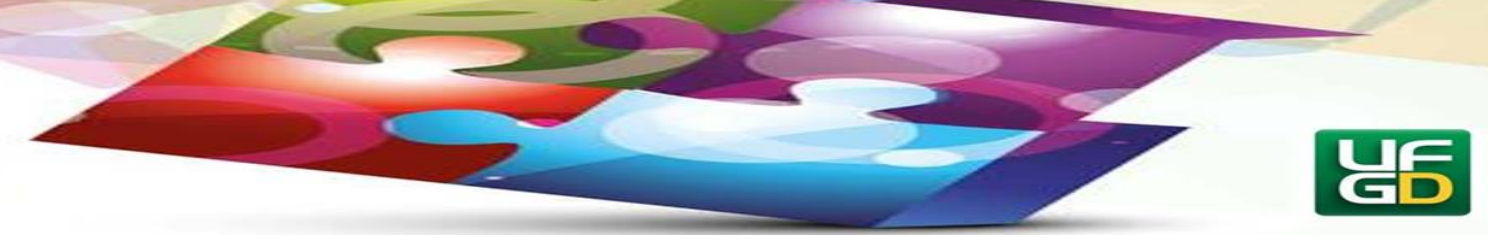

essenciais associados à sobrevivência e ao desenvolvimento de sua identidade (BRASIL, 1996, p. 13).

O referido documento nacional destaca ações para qualificação da Educação Infantil brasileira, tais como as questões ligadas às políticas públicas. Nesse contexto, a abordagem vygotskiniana, citada por Zacharias (2006) ressalta o papel do brincar na infância, ou seja:

[...] atividade específica da infância, em que a criança recria a realidade usando sistemas simbólicos. Essa é uma atividade social, com contexto cultural e social. É uma atividade humana criadora social, na qual imaginação, fantasia e realidade interagem na produção de novas possibilidades de interpretação, de expressão e de ação pelas crianças, assim como de novas formas de construir relações sociais com outros sujeitos, crianças e adultos (ZACHARIAS, 2006, p. 2).

Assim, a fase de escolaridade denominada Educação Infantil tem no brincar um fato muito importante. Deve-se levar em consideração o compromisso para com o caráter lúdico nas ações promovidas pelo professor no âmbito escolar, por se tratar de uma ferramenta indispensável no desenvolvimento da criança na sala de aula, contexto em que está diante da ampliação dos relacionamentos e de novas descobertas (BRASIL, 2016).

\section{Cantigas de Roda e Brincadeiras Cantadas - conceitos e caracterizações}

O que há em comum entre as cantigas de roda e as brincadeiras cantadas é a música. A música vai permeando:

O gesto, o movimento, o canto, a dança e o faz-de-conta. Brincar de roda, de ciranda, pular corda com ritmo de um canto são maneiras de estabelecer contato consigo próprio e com o outro, de se sentir único e, ao mesmo tempo, parte de um grupo, e de trabalhar com as estruturas e formas musicais que se apresentam em cada canção e em cada brincadeira (BRASIL, 1998, p. 70-71).

Para Vargas e Antunes (2010, p. 138), o brincar na primeira infância é necessário e quando administrado aos conteúdos e técnicas didáticas contribui para o processo de aprendizagem, por envolver esquema corporal, curiosidade, criatividade, espontaneidade, fantasia e imaginação das crianças. Segundo Brougère (1995), reforçando Cohn (2005) não há como pensar em ludicidade para crianças sem estudar como era a infância e quais os conceitos que a sociedade atribuiu a esta fase da vida, ao longo do tempo. Dito de outra forma, não se pode estudar a infância sem ressaltar as práticas lúdicas que eram usadas nos diferentes tempos 


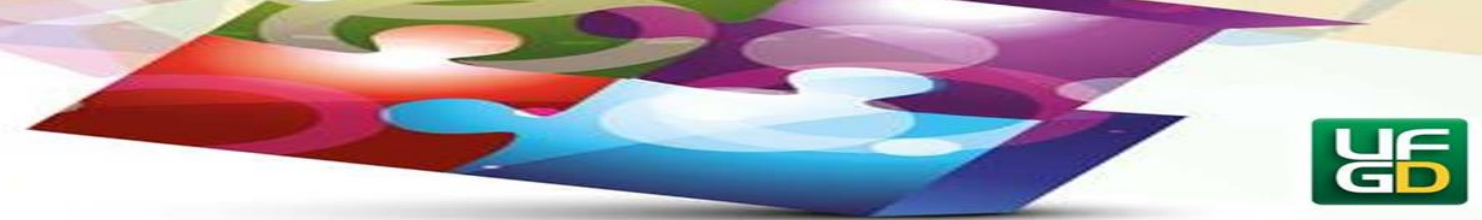

históricos e nas diversas culturas. O estudo sobre as infâncias e as práticas lúdicas, permite entender as diferenças entre as crianças. Este aspecto é pouco considerado, pois a maioria dos estudos que descrevem a prática lúdica, não associam a cultura e a história das sociedades de origem das crianças e das práticas lúdicas (BROUGÈRE, 1995; COHN, 2005).

No mesmo sentido está o fator musical. De acordo com Bréscia (2003), a música é um elemento de linguagem universal. Segundo dados antropológicos a música tem participação na história da humanidade, desde as primeiras civilizações, pois, sempre foi utilizada como parte de rituais, o que a caracteriza como um tipo de manifestação incorporada no costume das diferentes sociedades manifesta em casamentos, nascimentos, mortes, na recuperação de doentes e nos ritos de fertilidade.

Sintetizando, (1) a 'cantiga de roda' é um elemento constitutivo de todas as sociedades, cujas manifestações são realizadas na formação circular, podendo ser de mãos dadas ou não e acompanhadas por cânticos. As 'cantigas de roda' estão diretamente relacionadas com as 'brincadeiras de roda', sendo que os termos foram usados como sinônimos, pois os movimentos e gestos correspondem à letra cantada durante a prática em forma circular. De forma semelhante, (2) a 'brincadeira cantada' se diferencia por, necessariamente, não usar a formação em círculo/roda, embora mantenha a música. Ambas práticas com suas movimentações, gestos e cantos proporcionam o desenvolvimento da criança. Esses contextos são relevantes também como conteúdo escolar, pois auxilia no conhecimento artístico-cultural, social e educacional nos aspectos motriz intelectual e cognitivo (BARROS, 2010; GALLAHUE \& DONNELY 2008).

Culturalmente as 'cantigas de roda' e as 'brincadeiras cantadas' estão interligadas com uma melodia cujo ritmo favorece a assimilação das tradições orais de todas as culturas. Várias cantigas de roda e brincadeiras cantadas, conhecidas no Brasil, são de origem europeia, mais especificamente de Portugal e Espanha, advindas com a colonização, outras, no entanto vêm das diferentes culturas indígenas. Por meio das cantigas é possível conhecer costumes, cotidianos, festas típicas, comidas, paisagens e inclusive as crenças de cada povo (BARROS, 2010).

$\mathrm{Na}$ escola, a Educação Infantil adota práticas corporais que algumas crianças já 'conhecem de casa', tais como: "Atirei o pau no gato"; "Boi da cara preta"; "Borboletinha"; "Pirulito que bate bate"; "O sapo não lava o pé" entre outras. Muitas, no entanto, embora 


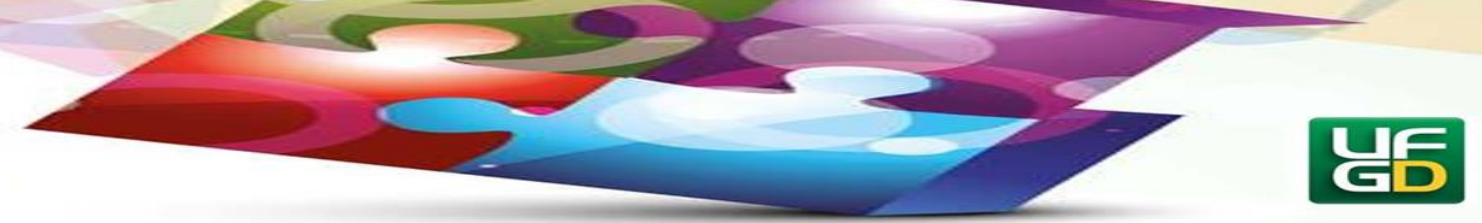

pertençam a cultura de vários povos, são transmitidas pela escola, como exemplo, destacamos: "Barata"; "Ciranda Cirandinha"; "A Canoa Virou"; "Caranguejo"; "Adoletá"; "Ai bota aqui, ai bota ali o seu pezinho"; "Cai, cai Balão"; “Alecrim”; entre outras. Há cantigas que sempre fizeram parte da vida dessas crianças, pois desde o ventre as mamães cantavam para seus bebês. Assim, pode-se compreender que há crianças que já nascem envolvidas nessa cultura; e, simultaneamente, pode haver crianças que, por diferentes motivos, não tiveram esse aporte cultural. A escola, na fase da Educação Infantil, pode vir a enriquecer o viver infantil com a prática de novas cantigas e a revitalização das cantigas já conhecidas.

\section{Considerações finais}

Com o objetivo de relatar as contribuições das cantigas de roda e das brincadeiras cantadas para a Educação Infantil, o estudo mostrou que a música, presente em ambas as práticas corporais contribuem para o desenvolvimento da capacidade de raciocínio e de memorização, adquiridos pela repetição da música e dos movimentos dançantes que acompanham as cantigas. As letras cantadas, tanto nas brincadeiras quanto nas rodas reportam, na sua maioria, à cultura das crianças, cujas histórias de vida podem estar marcadas por essas situações lúdicas.

Sobre a pergunta problematizadora: Quais contribuições as práticas corporais, cantigas de roda e as brincadeiras cantadas podem oferecer na formação da criança, nos aspectos social, motriz e afetivo? O estudo apontou o quanto são relevantes para o desenvolvimento didático, como também, promovendo o desenvolvimento social e motriz com fortalecimento cultural das diferentes realidades que permeiam a origem de cada criança.

Precisamos também estar atentos à seleção de cantigas de roda e brincadeiras cantadas a serem trabalhadas com as crianças, pois hoje com as questões sociais diversas, principalmente o bullying, muitas cantigas quando mal interpretadas estão sendo tachadas de "politicamente incorretas", ou seja, aquilo que promove, instiga ou incita a violência. Logo antes de tachar uma cantiga de roda ou uma brincadeira cantada como "politicamente incorreta" o/a professor deve realizar um trabalho de análise interpretativa para entender o que de fato traz aquela cantiga/brincadeira - fatores culturais superados, violência, ironias, formas jocosas de tratar as pessoas, entre outras. Os conteúdos, cantigas de roda e brincadeiras cantadas, devem ser 


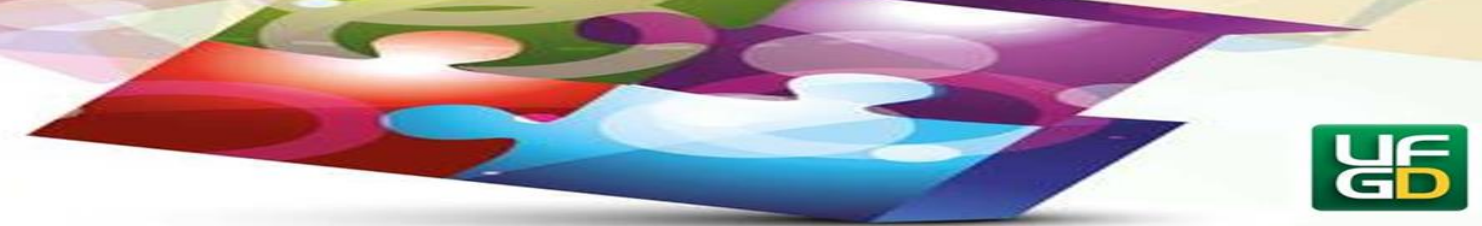

também planejados e discutidos entre os profissionais, para análise dos possíveis sentidos, das palavras diferentes e dos contextos a que se reportam. Tal exercício trará uma reflexão a respeito do contexto em que a música está inserida e qual a história que a letra esta passando. Essa seria uma forma de se manter a cultura das cantigas de roda e brincadeiras cantadas no ambiente escolar, evitando que elas se percam no tempo, que fiquem em desuso, ou sejam rejeitadas pela simplicidade, embora traduzam diferentes modos de vida.

\section{Referências}

ARTAXO, I. ; MONTEIRO, G. A. Ritmo e movimento: teoria e prática. 5 a . ed. São Paulo: Phort, 2013.

BARROS, M. de. As cantigas de roda na educação infantil. $4^{\text {a }}$. ed. Rio de Janeiro: Forense, 2010.

BRASIL. Referencial Curricular Nacional para a educação infantil. $10^{\text {a }}$. ed. Brasília, Distrito Federal: Editora do Senado, 1998.

BRASIL. Estatuto da Criança e do Adolescente (ECA). Lei n. 8.069, de 13 de julho de 1990, e legislação correlata [recurso eletrônico], $9^{\text {a }}$. ed. Brasília: Câmara dos Deputados, Edições Câmara, 2016.

BRASIL. Lei de Diretrizes e Bases da Educação Nacional. Lei no 9.394/96. 20 de dezembro de 1996. Disponível em: <http://portal.mec.gov.br/seb/arquivos/pdf/rcnei_vol1.pdf >. Acesso em: 05/05/2017.

BRASIL. Ministério da Educação. Base Nacional Comum Curricular. Proposta preliminar. Segunda versão revista. Brasília: MEC, 2016. Disponível em:

<http://basenacionalcomum.mec.gov.br/images/BNCC_publicacao.pdf >. Acesso em: 25 $/ 05 / 2017$.

BRÉSCIA, V. L. P. Educação Musical: bases psicológicas e ação preventiva. São Paulo: Átomo, 2003.

BROUGÈRE, G. Brinquedo e Cultura. Revisão técnica e versão brasileira adaptada por Gisele Wayskop. São Paulo: Cortez, 1995.

COHN, Clarice. Antropologia da Criança/Clarice Cohn. $2^{\text {a }}$. ed. Rio de janeiro: Jorge Zahar Ed, 2009.

CUNHA, N. H. S. Brinquedoteca: um mergulho no brincar. São Paulo: Vetor, 2001. 


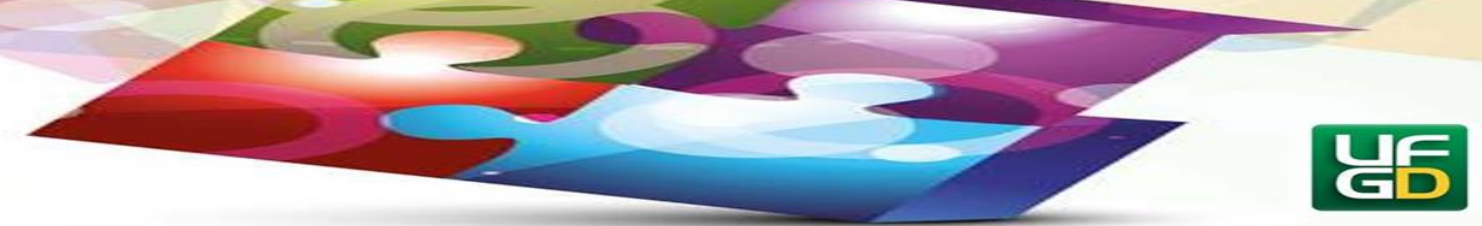

DICIONÁRIO Aurélio de português online. Disponível em: 〈https://dicionariodoaurelio.com/crianca〉. Acesso em: 30/10/2017

ELKIND, D. Sem tempo para ser criança: a infância estressada. David Elkind/trad. Magda França Lopes. $3^{\text {a }}$ ed. Porto Alegre: Artmed, 2004.

FALCÃO, J. L. C.; SARAIVA, M. C. Práticas corporais no contexto contemporâneo (in) tensas experiências /organizadores José Luiz Cirqueira Falcão, Maria do Carmo Saraiva. Florianópolis: Copiart, 2009. 304p. Disponível em: $<$ http://seguro.esporte.gov.br/arquivos/snelis/esporteLazer/cedes/praticasCorporais/praticasCo rporaisContextoContemporaneo.pdf >. Acesso em 29/09/2017.

FORTUNA, T. R. Sala de aula é lugar de brincar? In: XAVIER, M. L. M. e DALLA ZEN, M. I. H. (org.). Planejamento em destaque: análise menos convencionais. Porto Alegre:

Mediação, 2000.

FORTUNA, T. R. O brincar, as diferenças, a inclusão e a transformação social. Revista Atos de Pesquisa. Blumenau/Sc. V. 3, n 3, 2008. Disponível em: <http:// www. lume. ufrgs. br/ bitstream /handle/ 10183/33289/000726052.pdf?sequence=1>. Acesso em: 25/05/ 2017

FORTUNA, T. R. Vida e morte do brincar. In: ÁVILA, I. S. (org.) Escola e sala de aula: mitos e ritos. Porto Alegre: Editora da UFRGS, 2004.

GALLAHUE, D. e DONNELLY, F. C. Educação física desenvolvimentista para todas as crianças, adolescentes e adultos. São Paulo: Phorte, 2008.

GIL, A. C. Métodos e técnicas de pesquisa social. 4ª ed. São Paulo: Atlas, 2002.

KUZUYABU, M. Terapias com canto e música aliviam tensões físicas e emocionais e contribuem com o tratamento de diversas doenças, 2012. Disponível em:

$<$ https://noticias.uol.com.br/saude/ultimas-noticias/redacao/2012/12/29/terapias-com-canto-emusica-aliviam-tensoes-fisicas-e-emocionais-e-contribuem-com-o-tratamento-de-diversasdoencas.htm?cmpid=copiaecola >. Acesso em: 25/05/2017

LAKATOS, E. M. e MARCONI, M. A. Fundamentos de metodologia científica. $6^{\text {a }}$. ed. São Paulo: Atlas, 2003.

LIRA, B. M. P. Cantigas de rodas e parlendas: da brincadeira para alfabetização. 2016. Disponível em: https:// file. C:/Users/JOAOVITOR/Downloads/511-2162-1-PB.pdf>. Acesso em: 04/07/2017

LUCKESI, C. C. Educação, Ludicidade e Prevenção das Neuroses Futuras: uma proposta pedagógica a partir da Biossíntese. 2005. Disponível em:

<http://www.luckesi.com.br/artigoseducacaoludicidade.htm>. Acesso em: 25/05/2017

MARTINS, M. E. O. A Ludicidade na Educação. Porto Alegre, 2010. 


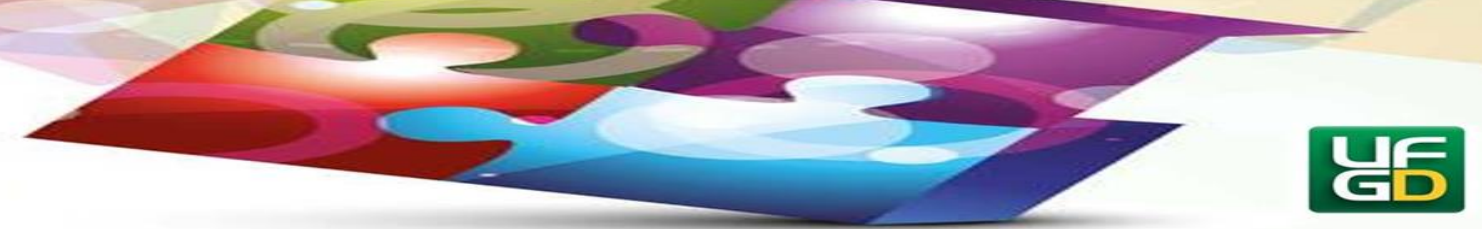

MAUSS, M. Técnicas corporais. Sociologia e Antropologia. São Paulo: Cosac \& Naif, 2003.

PALHETA, N. Cantigas de Roda são utilizadas no processo de construção do conhecimento infantil. 2007. Disponível em: <https://www.portal.ufpa.br/imprensa/noticia.php?cod=1104>. Acesso em: 25/05/2017.

QUEIROZ, L. R. S. Transmissão musical no contexto urbano de João Pessoa. In: Encontro Anual da Associação Brasileira de Educação Musical, 15., 2006, João Pessoa. Anais... João Pessoa: EDUFPB/ABEM, 2006, p. 691-701.

SILVA, A. M.; DAMIANE, I. R. Práticas Corporais: construindo outros saberes em Educação Física, v. 4. Florianópolis: Nauemblu, 2006.

SOUZA, S. S. Diretora da escola Ritmo Espaço de Dança, idealizadora da Valsa Maluca, Idealizadora do programa Slim Dance, professora de Ballet clássico, metodologia Vaganova, professora do Power Ballet e coreógrafa, 2015. Disponível em:

<http://sabrinadesouza.com.br/sample-page/>. Acesso em: 25/05/2017.

TEIXEIRA, S. R. O. Jogos, brinquedos, brincadeiras e brinquedoteca: implicações no processo de aprendizagem e desenvolvimento. Rio de Janeiro: Editora WAK, 2010.

VARGAS, J. C.; ANTUNES, H. S. Determinismo cultural frente à ludicidade na infância: conceitos e concepções paradigmáticas. Revista de Reflexão e Ação. V. 18, nº 2. Santa Cruz do Sul, 2010. Disponível em:

<https://online.unisc.br/seer/index.php/reflex/article/view/591/1937>. Acesso em: 30/092017.

ZACHARIAS, V. L. C. F. Jogo e educação infantil: mais sobre o jogo. 2006. Disponível em:<http://www.centrorefeducacional.pro.br>. Acesso em: 23/07/2017.

Enviado: 09/05/2018.

Aceito: 09/06/2018. 